\title{
Hypostatic ulcers in 47,XXY Klinefelter's syndrome
}

\author{
MARION S VERP, JOE LEIGH SIMPSON, AND ALICE O MARTIN \\ From the Section of Human Genetics, Department of Obstetrics and Gynecology, \\ Northwestern University Medical School, Northwestern Memorial Hospital, Chicago, Illinois, USA.
}

SUMMARY Hypostatic leg ulcers, probably secondary to vascular insufficiency, were observed in two adult men with 47,XXY Klinefelter's syndrome. The association between leg ulcers and 47,XXY Klinefelter's syndrome deserves increased attention because knowledge of the association may alert clinicians to an otherwise unsuspected chromosome abnormality.

47,XXY Klinefelter's syndrome is a relatively common disorder characterised by seminiferous tubule dysgenesis, androgen insufficiency, and various somatic anomalies. Less well known is that many adult onset disorders are also associated with Klinefelter's syndrome, such as diabetes mellitus, carcinoma of the breast, pulmonary diseases (bronchiectasis, bronchitis, emphysema), mitral valve prolapse, and varicose veins. ${ }^{12}$ In addition, idiopathic hypostatic leg ulcers may also occur with increased frequency in 47,XXY men. Howell ${ }^{3}$ recorded six cases and other investigators have made similar observations. ${ }^{4-8}$ We have observed hypostatic leg ulcers in two adult men who only late in life were discovered to have $47, \mathrm{XXY}$ complements.

\section{Case reports}

CASE 1

This 66-year-old white male, retired civil engineer, was admitted to Northwestern Memorial Hospital for treatment of chronic leg ulcers that had incapacitated him since 1974. He displayed schizoid tendencies and would not provide details regarding his family history; however, we are not aware of any relatives with related abnormalities. His childhood and young adulthood were apparently unremarkable. He never married but until 1974 he claimed normal libido, normal sexual activity, and good health. At that time an accident was said to have resulted in leg trauma that failed to heal properly and led to bilateral chronic leg ulcers. The patient also claimed that this accident injured his testes, resulting in testicular atrophy and impotence. He has not walked since 1974 because of discomfort from his ulcers.

\footnotetext{
Investigation by the authors supported in part by grants HD11021, HD02841, and HD8-2855 from NIH and grants from the March of Dimes.
}

Received for publication 1 July 1982.
Physical examination in 1978 revealed an obese $(112 \cdot 3 \mathrm{~kg})$ man with wide hips, female muscular habitus, sparse facial and axillary hair, and atrophic skeletal muscles of the lower extremities (gluteals, hamstrings). Multiple small ulcers were present on both lower extremities and a large longitudinal ulcer $(10 \times 2 \mathrm{~cm})$ was present on the left inner thigh. Sites of many previous skin grafts appeared raw and red. No varicose veins were present. The pubis-to-sole length $(99 \mathrm{~cm})$ was increased and the arm span was $4 \mathrm{~cm}$ shorter than his height of $195 \mathrm{~cm}$. His penis was normally formed but small and the testes were firm and small $\left(0.5 \mathrm{~cm}^{3}\right)$. Other positive findings included bronchitis, bilateral fifth finger clinodactyly, and generalised joint immobility; $x$-rays were consistent with diffuse idiopathic skeletal hyperostosis. The only neurological abnormality was hyperaesthesia of the lower extremities. No systemic disease existed to explain the presence of leg ulcers. Specifically, haematological and routine chemical studies were normal, including serum glucose.

Genetic evaluation was requested only after low testosterone levels (11 to $12 \mathrm{ng} / \mathrm{dl}$; normal 200 to 의 $1000 \mathrm{ng} / \mathrm{dl}$ ) were noted. Inexplicably, gonadotrophins were also low (FSH 3 to $4 \mathrm{IU} / 1$, normal $\leq 60 \mathrm{IU} / 1$; LH 9 to $16 \mathrm{IU} / 1$, normal $\leq 25 \mathrm{IU} / \mathrm{l})$. Chromosomal analysis of lymphocyte cultures (51 metaphases) by $\Omega$ GTG banding revealed a 47,XXY complement with $\tilde{\sim}$ no evidence of mosaicism.

\section{CASE 2}

A 43-year-old black male was admitted to Northwestern Memorial Hospital because of paranoid $\stackrel{\infty}{\rightarrow}$ schizophrenia, initially diagnosed 6 years previously. $\frac{T}{0}$ No other family members were known to have a $\frac{0}{\mathbb{D}}$ psychotic disorder or other genetic condition. $\stackrel{\$}{\mathbb{Q}}$ Early childhood was apparently unremarkable $\stackrel{\mathbb{Q}}{\varrho}$ except that he was noticeably taller than his peers. 
Puberty was remarkable in that normal virilisation did not occur; however, no evaluation was performed. Between the ages of 23 and 40 he intermittently received testosterone injections, although again no cause for his hypogonadism was ascertained. He never married. He claimed to have penile erections without ejaculations. Since childhood he had experienced chronic bilateral lower leg ulcers of uncertain aetiology. Varicose veins developed at the age of 41 and he underwent venous stripping of the right lower extremity in an attempt to relieve chronic varicosities.

Physical examination at the age of 43 revealed a massively obese $(151.8 \mathrm{~kg})$ man who was $192 \mathrm{~cm}$ tall; his arm span was $214 \mathrm{~cm}$, and lower segment length was $108 \mathrm{~cm}$. He had no facial hair, minimal axillary hair, a female distribution of pubic hair, a normal sized phallus, and small $(1 \times 1 \times 0.5 \mathrm{~cm})$ testes bilaterally. Gynaecomastia was not present. Neurological examination was unremarkable. Mild scoliosis of the thoracic spine was noted on $x$-ray. The lower extremities showed bilateral scaling of the skin, scars from old healed ulcerations, and bilateral non-pitting ankle oedema. With the exception of schizophrenia, no systemic illness was present; chlorpromazine was his only medication. Routine haematological and chemical parameters were normal, including serum glucose. Testosterone was only 13 to $20 \mathrm{ng} / \mathrm{dl}$, FSH 16 to $17 \mathrm{IU} / \mathrm{l}, \mathrm{LH} 9$ to $18 \mathrm{IU} / 1$.

Cytogenetic studies, requested because the attending physician suspected Klinefelter's syndrome, revealed a 47,XXY complement in lymphocyte cultures ( 50 metaphases) by GTG banding.

\section{Discussion}

Since 1977 this laboratory has ascertained six previously unrecognised cases of Klinefelter's syndrome. These six patients were aged 2 days, 8 days, 19 years, 43 years (case 2), 52 years, and 66 years (case 1) old. Among the four adults, hypostatic leg ulcers were prominent features in two. Although obviously a small sample, our findings suggest that hypostatic leg ulceration may be more common in $47, \mathrm{XXY}$ persons than previously suspected. Indeed, in another study, ${ }^{4}$ idiopathic hypostatic ulcers were present in four of $49(8 \%) 47, X X Y$ men, in four of 12 $(33 \%)$ men mosaic for $47, \mathrm{XXY}$, but in 0 of 102 adult men randomly selected from the general population. Zuppinger $e t a l^{5}$ noted stasis dermatitis in four of $24(14.7 \%)$ patients with Klinefelter's syndrome. Thus, the prevalence of hypostatic leg ulcers in 47,XXY males appears increased.

Hypostatic leg ulcers usually result from either peripheral vascular insufficiency (venous or arterial) or diabetes mellitus. Diabetes mellitus was not present in either of the cases reported here, nor in most of those reported by others. ${ }^{356}$ However, both of our cases were obese, as were several of the previously reported cases, and obesity predisposes to vascular insufficiency. Moreover, venous flow studies showed bilateral venous valvular incompetence in our case 2. In other reports the diagnosis of vascular insufficiency was made on clinical grounds, ${ }^{\mathbf{6}}$ by phlebography, ${ }^{6}$ or by arteriography, ${ }^{7}$ frequently in the presence of varicose veins.

The clinical significance of the above findings is that Klinefelter's syndrome should be considered in adult males who present with unexplained ulcers, particularly if the patient is also sterile. Although sterility per se may not be an issue in older males, knowledge that a given person has Klinefelter's syndrome would still be helpful clinically in alerting the primary physician to the increased likelihood of other adult onset disorders common in 47, XXY males, such as varicose veins, diabetes mellitus, pulmonary abnormalities, mitral valve prolapse, and breast cancer.

\section{Addendum}

Recent reports of subarachnoid haemorrhages in patients with Klinefelter's syndrome (Lancet 1982; ii : 380,491 ) are consistent with the hypothesis that a vascular abnormality may be the aetiology of hypostatic leg ulcers in Klinefelter's syndrome.

\section{References}

1 Simpson JL. Disorders of sexual differentiation: etiology and clinical delineation. New York, San Francisco, London: Academic Press, 1976.

2 Fricke GR, Mattern HJ, Schweikert HU. Mitral valve prolapse in Klinefelter syndrome. Lancet 1981 ;ii:1414.

3 Howell R. Hypostatic ulceration and Klinefelter syndrome. Br Med J 1978;ii:95-6.

4 Campbell WA, Newton MS, Price WH. Hypostatic leg ulceration and Klinefelter's syndrome. J Ment Defic Res 1980;24:115-7.

5 Zuppinger K, Engel E, Forbes AP, Mantooth L, Claffey J. Klinefelter's syndrome, a clinical and cytogenetic study in twenty-four cases. Acta Endocrinol 1967;54,suppl 113: 5-48.

6 Andersen KE. Sex chromosomal anomalies: a possible association with ieg ulcers. Clin Exp Dermatol 1979;4: 223-6.

7 Vogt HJ, Breit R. Ulcers cruris als symptom eines Klinefelter-syndroms. Hautarzt 1969;20:468-9.

8 Raso AM, Ressa PG, Levis P, Colombo R. Peculiaridad de las ulceras de los miembros inferiores en el sindrome de Klinefelter. Angiologia 1980;32:197-204.

Requests for reprints to Dr M S Verp, Prentice Women's Hospital and Maternity Center, Room 1102, 333 East Superior Street, Chicago, Illinois 60611, USA. 